\title{
Narrativas audiovisuales colectivas como vehículo de resignificación identitaria: implementando el vídeo participativo con jóvenes guatemaltecos/as
}

\section{Collective audiovisual narratives as a vehicle for identity resignification: implementing participatory video with Guatemalan youth}

Marta Figàs

Aalborg University, Dinamarca

$\left(\begin{array}{l}\text { Fecha de recepción: } 1 \text { de noviembre de } 2019 \\ \text { Fecha de aprobación: } 11 \text { de diciembre de } 2019\end{array}\right)$

DOI: http://dx.doi.org/10.15304/ricd.3.11.6381

\section{NOTAS BIOGRÁFICAS}

Marta Figàs es Licenciada en Comunicación Audiovisual por la Universitat Jaume I (UJI), Máster en Cooperación al Desarrollo (especialidad en Acción Humanitaria) por la misma universidad, cursando en la actualidad un Máster especialización en estudios migratorios (Global Refugee Studies) en la universidad Aalborg University (Copenhague, Dinamarca).

Contacto: mfigas19@student.aau.dk

\section{Resumen}

Enmarcado en el seno de la Investigación-Acción Participativa (IAP), el presente artículo, fruto de las Prácticas Externas llevadas a cabo en Máster en Cooperación al Desarrollo de la Universitat Jaume I de Castellón, recoge la experiencia de implementación de un proyecto de Vídeo Participativo con un grupo de cincuenta y cinco jóvenes estudiantes del Colegio San Pedro, en la localidad de San Pedro Yepocapa (Guatemala). La investigación toma a modo de principal problema a abordar el cómo los modos de representación dominantes proyectados a través de los medios de comunicación, influyen y dificultan la tarea de que los jóvenes guatemaltecos generen, se apoderen y construyan los suyos propios. Así pues, desde una perspectiva del audiovisual (técnica del VP) como herramienta para el cambio social y la transformación de comunidades; se buscó capacitar a estos jóvenes acerca de los entresijos que conforman la producción audiovisual, abordando junto con ellos y ellas temas como el lenguaje audiovisual, las fases de producción o la realización del storyboard. Aprender, en definitiva, a expresar en imágenes todas aquellas ideas que previamente habían plasmado en un papel. Dotarlos de estas herramientas posibilitó una búsqueda y construcción de formas de autorrepresentación genuinamente propias con las que se pudieran sentir conectados/as e identificados/as; rompiendo con el monopolio de los mass media como única institución poseedora de mecanismos de producción y difusión de sentido. Los resultados obtenidos muestran cómo los jóvenes realizaron una apropiación total del medio y los dispositivos audiovisuales; llegando a realizar piezas con una alta carga simbólica y narrativa. 


\section{Abstract}

Framed within the Participatory Research approach, this paper reflects the experience of the implementation of the Participatory Video technique within a fifty-five young students from the a group of fifty-five young students from the primary school 'Colegio San Pedro', in the town of San Pedro Yepocapa (Guatemala). The research takes as its main problem to address how the dominant modes of representation projected through the media, influence and hinder the task of young Guatemalans to generate, take over and build their own. Thus, from an audiovisual perspective (VP technique) as a tool for social change and community transformation, we sought to train these young people about the intricacies of audiovisual production, addressing with them topics such as audiovisual language or the phases of production or storyboarding. The main goal being to learn how to express in images all those ideas that they had previously put down on paper. By providing them with these tools the participants were able to search for and build their own forms of selfrepresentation with which they could feel connected and identified. Thus, breaking with the monopoly of the mass media as the only institution with mechanisms for producing and disseminating modes of representation. The results showed how participants made a total appropriation of the audiovisual language and devices; creating videos with actual meaningful and symbolic narratives. Indeed, the very act of self-representation through audiovisual devices proved to be a successful way of creation / re-negotiation of the participant's identities (both personal and cultural). The audiovisual narration of their own realities led to a strengthening of both the perception and the sense of belonging to their community.

\section{Palabras clave}

Autorrepresentación, vídeo participativo, subjetividad, comunidad, identidad colectiva.

\section{Keywords}

Self-representation, participatory video, subjectivity, community, collective identity.

\section{Sumario}

1. Introducción

1.1. El vídeo Participativo como herramienta facilitadora

2. Apunte metodológico

3. Líneas teóricas principales

4. Cuaderno de campo: el proceso creativo

\subsection{Participantes}

4.2 Gestación de ideas

\subsection{Salida al terreno}

4.4 Exhibición de sus obras audiovisuales

5. Análisis de los recursos audiovisuales

6. Conclusiones: a modo de reflexión final

\section{Summary}

1. Introduction

1.1. Participatory Video as a facilitating tool

2. Methodological note 
3. Main theoretical lines

4. Field notes: the creative process

4.1 Participants

4.2 Brainstorming

4.3 Working on the field

4.4 Exhibition of participant's final videos

5. Analysis of expressive and narrative aspects

6. Conclusions: final reflections 


\section{INTRODUCCIÓN}

En el mes de junio del año 2014, y enmarcado dentro del Lifelong Learning Programmes promovido por la Unión Europea, el Máster en Cooperación al Desarrollo de la Universitat Jaume I tuvo la oportunidad de auspiciar el Global Identity through Human Development: Summer School on Participatory Research Video. Esta experiencia previa impulsó la decisión de implementar la Técnica del Video Participativo (VP) en terreno, a través de las Prácticas Externas del Máster en Cooperación al desarrollo, que iban a tener lugar en la organización PROBIGUA de Guatemala. Se consideró que sería sumamente enriquecedor, tanto para la comunidad objeto de estudio como para el grupo que lo ponía en marcha, la implementación de la técnica del VP. Utilizada, en el caso objeto de estudio del del presente trabajo, a modo de herramienta de recogida de datos en campo, el VP supone un medio excepcional, "altamente flexible e inmediato a la hora de captar el arte, la poesía, el drama, la música, los testimonios personales (etc.) con una dimensión humana directa y un contacto frente a frente con los miembros de la comunidad". (Lunch y Lunch, 2006, p. 5).

Así pues, cuestiones acerca de la autorreferencialidad, la búsqueda de identidades individuales y colectivas, la construcción y representación del yo a través de lenguajes y narrativas audiovisuales (narrativas identitarias) o la generación de nuevos significados comprartidos, estudiados en el marco de un contexto socioeconómico y de diversidad cultural y étnica como es Guatemala, convertían esta oportunidad en un reto que, verdaderamente, ofrecía la posibilidad de adentrarnos en asuntos de gran calado.

Como apunta Joxe (2002, p. 78), "el mundo actual está unido por una nueva forma de caos, un caos imperial, dominado por el imperium de los Estados Unidos, aunque no controlado por éste. Carecemos de las palabras para describir este nuevo sistema, si bien estamos rodeados por sus imágenes". En esta misma línea, encontramos fenómenos como el imperialismo (o colonialismo) cultural, los cuales dan buena muestra de cómo las industrias culturales occidentales se han hecho con el monopolio en cuanto a la construcción y difusión de significados, modos de vida y discursos que operan en nuestro imaginario colectivo. Un sector altamente vulnerable a todos estos estímulos mediáticos es la juventud, pues es durante la ado- lescencia cuando se comienzan a conformar nuestras propias identidades mediante mecanismos psicosociales que median en su construcción (tales como los vínculos afectivos, las transiciones vitales, la identificación simbólica, etc.)

\subsection{EL VÍDEO PARTICIPATIVO COMO HERRAMIENTA FACILITADORA}

Como se viene apuntando, la metodología escogida para llevar a cabo la investigación objeto de este trabajo ha sido la Investigación Acción Participativa (IAP). A modo de breve descripción, se puede decir que la IAP es una metodología que persigue la transformación social como objetivo último. Para ello, se lleva a cabo un proceso colectivo de reflexión y debate en el seno de los grupos, comunidades o sociedades, mediante los que se consigue la generación conjunta de conocimientos y sabe-res. (FalsBorda, 1985).

Así pues, debido a la idiosincrasia de la misma (considerar a la población como principal agente social de cambio), resulta una métodología idónea para abordar los objetivos propuestos en este trabajo. Y por ello la persona encargada de implementar este tipo de técnicas y metodologías se adscribe dentro de un rol de facilitador/a dentro de las comunidades, posibilitando la articulación social y favoreciendo la generación de nuevos espacios de debate y generación de conocimiento endógeno.

Enmarcada dentro de la Metodología de la IAP se encuentra la técnica participativa escogida para la recogida de datos en este proyecto: la Técnica del Vídeo Participativo (VP en adelante). Siguiendo las ideas de los hermanos Lunch (2006, p. 12), "Ios vídeos participativos contemplan un conjunto de técnicas que buscan lograr la participación de un grupo de personas o una comunidad en el diseño y la creación de su propia película." El vídeo participativo es, en esencia, un proceso de intervención social que tiene como objetivo la transformación de la comunidad. Supone una herramienta para la reflexión en torno a la identidad, a la organización y a la auto representación de los sujetos en formatos audiovisuales. Dicho cambio es siempre liderado por la propia comunidad, a través de un verdadero ejercicio de emancipación logrado a través del dominio de las herramientas audiovisuales; la cuales se convierten en instrumento clave para la formulación de sus propios discursos. Se considera, pues, 
idónea la aplicación de la misma en el contexto en el que nos encontramos, debido a que resulta un mecanismo de intervención social, visibilización de problemáticas y de mediación de conflictos. Facilita la auto representación de los sujetos en formatos audiovisuales, la autorregulación en la producción de su propio discurso y la negociación de intereses para la generación de significados comunes.

Navegar junto con las participantes a través de los entresijos que conforman la producción audiovisual, abordar conjuntamente temas como el Lenguaje Audiovisual, las fases de producción, la realización del storyboard (en definitiva, aprender a expresar en imágenes todas aquellas ideas que previamente han plasmado en un papel) convierten al VP en una potente herramienta que facilita la búsqueda y construcción de formas de auto representación propias con las que las personas tengan la posibilidad de sentirse genuinamente conectados/as e identificados/as.

Abriendo, así, senderos dirigidos a una paulatina pero consciente ruptura con el monopolio de los mass media como única institución poseedora de mecanismos de producción y difusión de sentido; al tiempo que se van generando narrativas alternativas frente a los discursos homogeneizadores que perpetúan y normalizan determinados modos de ser y estar en el mundo.

\section{APUNTE METODOLÓGICO}

El uso de la cámara como herramienta para producir datos investigables es algo relativamente reciente. Tradicionalmente, las ciencias sociales han adoptado un enfoque marcadamente logocéntrico respecto al análisis e investigación de la realidad social y cultural; esa "curiosa idea Occidental de que la realidad tiene un dialecto en el que prefiere ser descrita" (Geertz, 1989 , p. 140), relega la imagen, dentro de las disciplinas sociales, a un segundo plano. Se infravalora la capacidad de lo audiovisual como un nuevo prisma interpretativo, y las imágenes recogidas suelen ser, en la mayoría de los casos, privadas de un análisis posterior del que extraer información útil.

Por tanto, asumiendo nuestra subjetividad como investigadores y sin aras de velar el carácter interpretativo que el observador proyecta en el objeto de estudio, nos serviremos de la metodología del análisis discursivo para observar el uso del lenguaje y los enunciados construidos por los/as participantes A través de ésta, se expondrán de manera descriptiva las principales variables expresivas y narrativas empleadas en los vídeos El Café y La política. Elecciones generales. Éstos fueron seleccionados de entre los ocho vídeos existentes debido a su carácter paradigmático dentro de la realidad social guatemalteca; así como por la técnica final aplicada, ajustada al propósito de la investigación.

La psicología social discursiva (postura empleada en nuestro corpus teórico) se basa en tradiciones como la semiótica, la etnometodología (Garfinkel, 1967) o la teoría de los actos del habla (Austin, 1962). Se trata pues de una perspectiva relativamente reciente y prioritariamente británica que fue directamente influenciada por el conocido como pensamiento del "segundo Wittgenstein" y consecuentemente por el giro lingüístico (Ibáñez, 2003) que volvió la mirada al lenguaje y advirtió la imposibilidad de un verdadero trabajo conceptual de la filosofía sin el previo análisis de éste.

\section{LÍNEAS TEÓRICAS PRINCIPALES}

El presente artículo se enmarca en el área de estudio de la Comunicación para el Desarrollo. Ésta entiende la comunicación como un proceso liberalizador y un elemento fundamental para el desarrollo de las comunidades. Autores como Ramiro Beltrán o Mario Kaplún, pertenecientes a la corriente crítica de la Escuela Latinoamericana, impulsaron sendas ideas acerca de la Comunicación para el Desarrollo desde los medios de masas, (Beltrán, 1970) y sobre nuevas formulaciones en torno a la democratización de la comunicación y de su utilización en la formación (Kaplún, 1998). Partiendo de estas ideas, podemos tomar el dispositivo audiovisual como una herramienta que empodera a la comunidad, situándose ésta como formuladora de mensajes que persiguen influir en los comportamientos y modos organizativos de la misma.

En definitiva, se puede afirmar que la técnica del VP se enmarca dentro de lo que es considerado como prácticas comunicativas para el cambio social. Ante la pregunta que plantea Escobar (2004, p. 29): “¿Es posible pensar que las nuevas tecnologías, por su propio carácter y en las manos de grupos subalternos, nutran nuevas prácticas del ser, el conocer y el hacer?", confiamos que la presente experiencia con el VP sea uno de tantos ejemplos que se traduzcan en un sí como respuesta. 
Intentar constatar cómo a través de técnicas participativas se pueden generar modos alternativos de re-significarse y representarse en el seno de una sociedad, fue uno de los objetivos centrales durante todo el proceso de implementación del VP. Abordar pues, de manera suscita, el tema de la construcción de la identidad como elemento imprescindible para que se pueda dar el acto de (auto) representación del individuo ayudará en la comprensión de este fenómeno.

Entendiendo la identidad como fenómeno narrativo, uno de los pensadores contemporáneos del siglo XX que más ha aportado a la construcción de la identidad a través de la narración ha sido el teórico francés Paul Ricoeur (1985). En su obra en tres volúmenes Tiempo y Narración, el filósofo, a través del análisis del relato, expone el concepto de identidad como una unidad móvil y dinámica; afirma que, el ser humano, es en sí narratividad; y que somos producto de un entramado de relatos, pasados y presentes, históricos y de ficción; a partir de los cuales narramos la historia de nuestras propias vidas. A través del lenguaje, de la palabra del otro mediante el diálogo, Bajtín (1981) interpreta la identidad como un acto retórico de comunicación mediante el cual, los interlocutores tratan de persuadirse mutuamente respecto a un tema/persona concreto. Continuando con el binomio narrativa/identidad, otro autor que revolucionó el campo de la psicología cognitiva a este respecto, fue el estadounidense Jerome Bruner. El psicólogo sostiene una visión constructivista de la realidad, afirmando que "no podemos conocer una realidad prístina; que no existe ninguna; que toda realidad que creamos se basa en la transmutación de alguna "realidad" anterior que hemos tomado como dada. Construimos muchas realidades, y lo hacemos desde diversas intenciones:

Las construimos a partir de miles de formas en las cuales estructuramos la experiencia, ya sea la experiencia de los sentidos, la experiencia profundamente codificada en símbolos que adquirimos al interactuar con nuestro mundo social, o la experiencia sustituta que logramos con la lectura. (Bruner, 1986, p. 159).

De esta manera, y especialmente durante la adolescencia, la identidad es construida a través de mecanismo como las identificaciones simbólicas (Pol, 2002) (es decir, sintiéndose miembro de un determinado grupo social) y las acciones más cotidianas mediante las que el individuo se relaciona con grupos sociales determinados (a los que se vincula).
Según Bourriaud (2004) interpretamos la realidad construyendo un montaje de sus elementos, de lo que nos llama la atención a nuestro alrededor, y le damos uno u otro sentido según cómo los ponemos en relación con los otros elementos que vamos recopilando. Por tanto, los sujetos viven e interpretan su realidad como si ellos mismos fueran los actores y actrices en un set de rodaje, en el que ellos mismos son los directores de sus propias vidas y se encuentran permanentemente generando su relato particular e intransferible.

Se convierte pues en tarea apremiante la desmitificación de la pantalla de televisión como única poseedora de legitimidad para la generación y reproducción de significados y discursos "válidos". Es por tanto necesario un [re]apoderamiento de los lenguajes (audiovisuales, y digitales en un más amplio espectro); así, a través del aprendizaje y de la de-construcción de los entresijos que esconden las narrativas audiovisuales (en el caso que nos ocupa, a través de los talleres en capacitación audiovisual) más mainstream, conseguimos adentrarnos en un mundo de posibilidades expresivas inaccesibles para el gran público, cuyo lenguaje ya no supone un enigma y cuyas reglas, una vez deslegitimadas y desmontadas, un obstáculo para apropiarnos del medio y convertir a los/as participantes en productoras de sus propios relatos.

\section{CUADERNO DE CAMPO: EL PROCESO CREATIVO}

\subsection{PARTICIPANTES}

Un total de cincuenta y cinco estudiantes con edades comprendidas entre los 14 y los 15 años conformaron el grupo de jóvenes participantes en esta experiencia de VP. 22 mujeres (49\%) y 23 hombres (51\%) Alumnos/as todos ellos/as del grado $3^{a}$ Básico (Sección A y B), del Colegio San Pedro, de la localidad de San Pedro Yepocapa (Chimaltenango, Guatemala).

\subsection{GESTIÓN DE IDEAS}

Después de mantener una reunión junto con el personal docente, el director del centro y el supervisor de la organización; consideramos más adecuado aplicar la metodología del Video Participativo únicamente en las clases de los alumnos/as del último curso y, por tanto, de 
mayor edad en el centro: estudiantes de Tercero Básico con edades comprendidas entre los 14 y 15 años. Además, se decidió también que, debido al carácter social y marcadamente audiovisual del proyecto, las clases de presentación de la idea, conformación de grupos y temas a tratar, así como también los Talleres de Capacitación Audiovisual, iban a ser impartidas en las horas correspondientes a las asignaturas de Ciencias Sociales, Comunicación y Lenguaje y Computación.

Así pues, ya que contamos con un total de 55 alumnos/s divididos en dos clases $\left(3^{\circ} \mathrm{A}\right.$ y $\left.3^{\circ} \mathrm{B}\right)$, con un total de 29 y 26 estudiantes respectivamente, optamos por mantener los grupos y crear grupúsculos dentro de cada clase. De esta manera, una vez realizada la clase inicial en la que se les habló a los jóvenes acerca del proyecto y de qué se esperaba de ellos/as, nos pusimos manos a la obra y conseguimos conformar 4 grupos en cada una de las clases, con un total de 8 grupos que se encargarían de diseñar y llevar a cabo su propio vídeo grupal.

Aunque inicialmente resultó algo complicado; instamos e invitamos a los jóvenes a formar grupos equilibrados, idealmente con la misma cantidad de hombres y mujeres y, a poder ser, en los que trabajaran con compañeros/as desconocidos con quienes todavía no habían tenido la oportunidad de trabajar anteriormente.

De esta manera, una vez decididas las horas y clases que íbamos a dedicar al proyecto, iniciamos el día 22 de enero con las clases de Ciencias Sociales que tanto el grupo de $3^{\circ} \mathrm{A}$ como el de $3^{\circ} \mathrm{B}$ tenían ese mismo día. Consideramos conveniente hablarles sobre mi procedencia, los estudios que había realizado en España y el motivo que me traía a su localidad, San Pedro Yepocapa, para implementar el proyecto de Vídeo Participativo.

Los jóvenes mostraron una actitud muy receptiva des del primer momento: aunque su curiosidad y desconocimiento sobre el tema los paralizó en primera instancia; conseguimos, junto con el profesor de Ciencias Sociales que compartieran y verbalizaran sus dudas y miedos al respecto. Una vez pasado este trance, y ya realizados los grupos; pedíamos a los/as participantes que, sentados en grupos, comenzaran un diálogo grupal, en el que se diera una lluvia de ideas y debatieran acerca de cuál iba a ser el tema sobre el que les gustaría que versaran sus vídeos.

Con la ayuda del profesor Orlando, íbamos supervisando cada uno de los grupos, de mane- ra que nos iban planteando diferentes cuestiones a resolver, y les íbamos aconsejando y asesorando acerca de cómo podían abarcar sus historias. Finalmente, en la última parte de la clase, les pedíamos que llegaran a un consenso entre todos/as los/as componentes de grupo, y me plantearan el tema (siempre temporal y modificable) sobre el que iba a tratar cada uno de los videos grupales. Como única premisa, se les indicó que eligieran un tema que, desde su punto de vista, atañía a su comunidad de algún modo; y que, además, debían enfocar el vídeo desde una perspectiva crítica acerca del tema escogido.

Durante la primera sesión del Taller de Capacitación Audiovisual, decidimos utilizar, como no podía ser de otra manera, recursos audiovisuales que ilustraran de una manera sencilla conceptos como "Lenguaje Audiovisual", "Planos", "Movimientos de cámara", "Angulación", "Sonido" etc. De esta manera, a través de la proyección de 3 vídeos, los propios alumnos tuvieron unas nociones básicas acerca de las herramientas y el lenguaje específico de que se valen los realizadores y directores en sus producciones audiovisuales.

Seguidamente, decidimos también compartir con ellos/as un pequeño corto que sirvieran como mensaje inspirador y catalizador. Se trata de un corto documental realizado por unos veinte jóvenes pertenecientes a un barrio a las afueras de Buenos Aires ("Pibes rodando"), junto con la ayuda de una asociación civil del mismo. La idea principal era "des estigmatizar" la imagen que de ellos/as se proyecta en los medios de comunicación convencionales, mostrando otras realidades y maneras de vivir en solidaridad que se dan en el barrio.

Después del visionado, los/as alumnos/as se mostraron conmovidos y, de alguna manera, reflejados. Algunos/as me preguntaron si ellos/as iban a ser capaces de realizar algo así, otros incluso me plantearon temas alternativos para sus videos (más sensibles y comprometidos con su realidad social y colectiva).Para la segunda sesión del taller, decidimos pedirles a los jóvenes que trajeran los dispositivos con los que iban a realizar sus vídeos (idealmente, cámaras compactas de fotografía con modalidad de vídeo); de manera que perdieran el miedo a las cámaras y tuvieran un primer contacto con ellas.

A modo de pequeña práctica, les pedimos que se reubicaran en grupos, para así proceder de la siguiente manera: 
- Conversamos con los participantes, averiguamos qué historias les gustaría contar. Utilizamos actividades creativas para estimular las ideas, siempre fortaleciendo su confianza, alentando y elogiando sus ideas.

- Les pedimos que dibujaran entre 4 y 6 viñetas (storyboard).

- Les preguntamos acerca de cómo les gustaría presentar sus historias. Les pedimos que dibujaran un boceto en la primera viñeta (siempre una imagen sencilla: figuras con líneas, trazos rápidos, los detalles nos son necesarios).

- Una vez acabadas cada una de las viñetas, les preguntamos: ¿Quién está hablando aquí?/ ¿Quién está filmando la toma?/ ¿Dónde realizarán la filmación?

- Ahora, cada uno de los grupos procede a filmar las tomas en el orden planificado en las viñetas ilustradas.

Dado que, para la realización y puesta en marcha de este proyecto, era indispensable que los/las estudiantes contaran con algún dispositivo con modalidad de vídeo (celular, cámara fotográfica o de vídeo); optamos, junto con los profesores, por intentar que cada uno de los 8 grupos dispusiera de una cámara (idealmente de fotos/vídeo) perteneciente a uno de los integrantes del grupo. De esta manera, aunque al principio había reticencias por parte de ciertos grupos, conseguimos que trajeran a las clases sus propios dispositivos; de modo que se responsabilizaron y se hicieron cargo de su cuidado y buen uso.

\subsection{SALIDA AL TERRENO}

Una vez los jóvenes ya habían adquirido las competencias conceptuales, técnicas y procedimentales necesarias para la creación de sus propios vídeos, llega el momento de llevar ese aprendizaje a la práctica.

Así pues, durante las primeras semanas de febrero, cada uno de los grupos coordinaba salidas al exterior junto conmigo, de manera que se les acompañaba en busca de las localizaciones (previamente establecidas en sus escaletas y planes de rodaje a modo de viñetas ilustradas) y les daba a su vez una supervisión, con el objetivo de asesorar en todo momento a los jóvenes. Para la elaboración de sus planes de rodaje, se dio una negociación entre los miembros del grupo respecto a la selección de los planos y del modo que serían finalmente contados.

Además, durante esta fase se llevaron a cabo diferentes ejercicios de reflexión acerca del poder de la imagen, ya que entendieron que, a través de sus vídeos y de aquella selección de su realidad que decidieran mostrar, iban a llevar a cabo una representación de ellos mismos y su mundo. El video dejaba de ser algo ajeno y externo para convertirse en una expresión autorreferencial para ellos. Se dio, en muchas ocasiones, un proceso de búsqueda de identidad que los uniera (una mirada colectiva) y al mismo tiempo, sobre la que existiera un acuerdo consensuado al que se llegaba a través de un ejercicio democrático.

De esta manera, decidimos adoptar una dinámica en la que se pudieran Ilevar a cabo, de manera más o menos simultánea, las tres etapas de: grabación, visionado y edición. En ocasiones, y cuando el dispositivo de vídeo lo permitía, realizábamos visionados sobre el terreno inmediatamente después de la realización de la toma. De manera que, generalmente, se despertaba en ellos una actitud autocrítica y un afán de superación que se contagiaban unos a otros. Esto animaba al equipo en su conjunto a realizar tantas tomas como fuera necesario hasta obtener los mejores resultados posibles.

Ya que, tanto los profesores más involucrados (valga señalar que no había ni una sola mujer en la plantilla docente) en el proyecto como la facilitadora, instaron a los/as alumnos/as a que aprovecharan la oportunidad que estos vídeos les brindan para dar voz a los y las Yepocapenses, la realización de entrevistas fue unos de los pilares básicos para la gran mayoría de grupos. A través de éstas, los/as jóvenes tuvieron la oportunidad de recoger e inmortalizar testimonios de ciertas personalidades de su municipio; encontrándose cara a cara con una parte de la historia viva de Yepocapa (la sabiduría de los más mayores). De esta forma, tuvieron la oportunidad de explorar en mayor profundidad acerca de las problemáticas de su propia comunidad (de las posibles soluciones que podrían darse) y cómo escenificar éstas audiovisualmente.

\subsection{MUESTRA FINAL DE SUS PROYECTOS AUDIOVISUALES}

Como fase final dentro del proceso de elaboración de los vídeos grupales, se decidió junto 
con el personal docente llevar a cabo un evento público y abierto (podían asistir tanto alumnos del centro como padres y madres) durante el que los participantes tuvieran la posibilidad de presentar ante sus compañeros/as el producto final fruto de casi tres meses de trabajo constante. Con la ayuda de alumnos/as y profesores, se consiguió instalar una gran tela blanca en un punto estratégico en el que no incidiera la luz muy directamente, de esta manera, uno de los profesores se encargaba de proyectar los vídeos con el cañón, los cuales, presentados durante todo el evento por dos alumnos voluntarios, iban siendo introducidos por sus respectivos autores (explicando, a través de un discurso oral previamente elaborado, quiénes eran los integrantes del grupo y cuál era el objetivo principal que perseguían con el vídeo).

Además, el acto fue cubierto en su totalidad, siguiendo así con el proyecto emprendido por un amante del pueblo de Yepocapa (José España, director de la televisión local Canal 28), cuyo objetivo es recoger todos los eventos de cualquier índole que son considerados de interés local; para, más tarde, emitirlos a través de su canal. Con este tipo de iniciativa, José y su cámara/altavoz se convirtieron para los/las participantes en la constatación de que, efectovamente, su comunidad muestra un interés por ver y escuchar los relatos audiovisuales que con tanta ilusión se proyectaban.

\section{ANÁLISIS DISCURSIVO DE LOS RECURSOS EXPRESIVOS Y NARRATIVOS}

Para emprender el análisis interpretativo de los recursos expresivos y narrativos, optaremos por abordar, en primer lugar, la pieza titulada $L a$ Política. Elecciones Generales ${ }^{1}$. Iniciando con la puesta en escena del fragmento, por lo que respecta a los tipos de planos encontrados, cabe señalar que, al tratarse de un vídeo con formato de entrevistas; existe una mayoría de planos americanos (mostrando al personaje de las rodillas hacia arriba) a través de tomas fijas. No obstante, cabe señalar la existencia de un par de primeros planos, que, mostrando en la pantalla únicamente el rostro del entrevistado, denotaban una intención expresiva por transmitir las emociones que el personaje estaba sintiendo en el momento de la entrevista. Así pues, por lo que respecta al plano y proxémica de la cámara, se puede afirmar que, si bien no se ha dado una gran diversidad de tipos de plano; los realizadores han sabido adaptarlos a sus necesidades; utilizando el primer plano con sabiduría, consiguiendo reforzar los testimonios verbales de los ciudadanos/as con la expresión facial de sus rostros.

Respecto al ángulo utilizado, se da, en todos los planos excepto uno, una angulación normal. De esta manera, cabe señalar que el ángulo de toma de un sujeto influye en las sensaciones que puede provocar ese personaje en el espectador; por lo tanto, la elección de este tipo de angulación normal se traduce en la intención de trasladar al espectador la idea de que los personajes se sitúan a su mismo nivel (físico, pero también jerárquico, de autoridad o moral). Se observa cómo los/as realizadores pretenden hacer llegar al público la sensación de que aquello que los testimonios cuentan, es algo verosímil y honesto; que atañe al total de la población yepocapense, y que debería ser escuchado con respeto, pero desde un enfoque horizontal de "igual a igual; ciudadano a ciudadano".

Por lo que respecta a la escena, no existe apenas movimiento de los personajes dentro de las mismas, por lo que la escasa relación narrativa entre la sucesión de éstas indica la intención de transmitir al espectador un producto audiovisual más cercano al reportaje a pie de calle, cuyo estilo pretende ser neutral y cuyas ideas son siempre arrojadas a través de los testimonios de los personajes entrevistados. De esta forma, aquello que se podría catalogar como "línea editorial" de la pieza, se encuentra intencionadamente oculto. Así, vemos que el grupo realiza un verdadero acercamiento a la Voz de sus conciudadanos, convirtiéndose en altavoz de su propia comunidad y consiguiendo hacerse eco del debate político (ante unas elecciones presidenciales inminentes), que se viene dando en las calles de Yepocapa y otros espacios públicos municipales.

En línea con la voluntad de asepticidad que se señalaba anteriormente, los testimonios de los entrevistados se convierten en el "narrador principal" del vídeo. Además, este estilo neutral es reforzado por las enunciaciones delegades que se dan a través de las preguntas formuladas con rótulos. El hecho de que no se observe cómo la entrevistadora realiza la pregunta, encargando de éste cometido a la pantalla (entendida ésta como mecanismo representacional), persigue el objetivo de dotar a las preguntas de un mayor grado de objetividad. Cabe señalar el tinte (lenguaje) marcadamente sexista que emanan algunas de las preguntas (formuladas, todas ellas, en género masculino), como por ejemplo: ¿Usted cree que sea importante que el padre de 
familia dé a conocer a sus hijos el valor del voto o sufragio?

Además de reflejar características de naturaleza social (en este caso, refleja la existencia de un sistema patriarcal dentro de las sociedades guatemaltecas); es interesante el modo como, mediante los usos de la lengua, se pueden advertir fenómenos como la relegación de la mujer a un ámbito más privado o doméstico; ocupándose en este caso "el padre de familia" de la educación en valores de sus hijos/as: "concienciar a los hijos del valor del voto". En este orden de cosas, apuntar que, tanto en el vídeo que nos ocupa como en el que más adelante trataremos, se observa idéntica jerarquización por género en su representación grupal:

Por lo que respecta al sonido y a la música durante el vídeo, sólo se reconoce una única canción con la que se abre el vídeo, perteneciente al cantante estadounidense Switchfoot. Observamos, una vez más, como las influencias culturales que proceden del exterior son interiorizadas y apropiadas por los jóvenes, llegando incluso a hacerse un uso de ellas para procesos de autorrepresentación como éste. Respecto al montaje de la pieza, se puede afirmar que la ausencia de un montaje interno responde al género escogido por los realizadores; ya que no se necesita de una narración interna de personajes al interior de los planos para realizar un producto basado en entrevistas a pie de calle. Así pues, el montaje a posteriori llevado a cabo, ha sido la herramienta mediante la cual los realizadores han dotado del sentido pretendido a la pieza. En líneas generales, se observa cómo este primer vídeo analizado se presenta como un intento exitoso de trasladar, a través de las imágenes, unas formas de observar el panorama político latente que caracterizan a la sociedad guatemalteca en general (observándose un gran hartazgo y desapego respecto a la clase política y sus instituciones). Mediante el uso eficiente de elementos pertenecientes al Lenguaje Audiovisual, el vídeo consigue alzarse como plataforma desde la cual diversas ideas locales acerca del voto y su importancia en las próximas elecciones presidenciales (en septiembre de este mismo año 2015), cobran valor y son susceptibles de ser trasladadas a la opinión pública o a las administraciones locales tomadoras de decisiones.

A continuación, se llevará a cabo idéntico procedimiento para la elaboración de la interpretación de los resultados obtenidos a través del análisis discursivo del vídeo, titulado El café2. A diferencia del vídeo analizado con anterioridad, la pieza El café, cuenta con una puesta en escena rica en planos y tomas varias (tanto fijas como en movimiento). Así, mediante la utilización de planos de tipo general, americano, conjunto o en detalle, los realizadores consiguen transportar al espectador a otra época; sin renunciar a la parte más documental de su propósito, que más adelante se abordará.

Continuando con esta idea, cabe apuntar que, desde el primer plano fijo con el que se abre la pieza en cuestión, se detecta un propósito narrativo mediante la introducción de unos personajes (realizadores/as caracterizados/as) que van a ir acompañando paralelamente el relato más expositivo. Así, el uso de una historia introductoria que nos transporta a una escena costumbrista sirve al espectador para diferenciar la historia ficcionada de la parte más documental y descriptiva del vídeo. Esta determinación por no renunciar a ninguno de los dos géneros (ficcional y documental), denota cómo el grupo ha apostado por realizar una representación que refleje aspectos más tradicionalmente identitarios que los unen con su comunidad. Es necesario señalar que el cultivo de café, junto con el de azúcar, banano y cardamomo, supone una de las bases agrícolas de la economía guatemalteca. Su tradición se remonta a los inicios del 1800, y desde entonces, la caficultura se ha convirtiendo en la actividad productiva más importante. De este modo, convertir este producto en protagonista del vídeo que nos ocupa, no es baladí. Manifiesta un deseo por adentrarse en temas de ámbito regional que afectan el día a día y el buen vivir de los habitantes de San PedroYepocapa.

Por lo que respecta al narrador, se puede considerar en este caso que los que se alzan como "narradores principales" son los mismos realizadores/personajes; dirigiendo su presentación (y su mirada) directamente al público receptor: -Saludos, somos el grupo Yepocultura...

-Y a través de este vídeo daremos a conocer sobre le tema del café.

-Lo que nosotros pretendemos es dar a conocer su proceso y su almacenamiento...

-Ya que es la producción de Guatemala y de nuestro bello pueblo: San Pedro Yepocapa.

Una vez hechas las presentaciones iniciales, se ofrece el testimonio de José León Yután, caficultor yepocapense que se encarga de explicar en qué consiste el proceso de plantación de las matas de café; convirtiéndose ésta en la primera enunciación delegada en la pieza audiovisual. Seguidamente, articuladas junto con la historia 
costumbrista, se entretejen otras tres entrevistas a señores de la localidad, a quienes se les plantea:

\section{- ¿Por qué consumimos café industrializado?}

- ¿...si nosotros poseemos de nuestros propios cultivos?

De esta manera, a diferencia de la pieza anteriormente comentada, los autores del vídeo se alzan como narradores del relato; proclamándose como autores detrás y ante las cámaras, transmitiendo un propósito abiertamente expositivo a través del que juegan con la representación de su estilo de vida más folclórico; poniendo, a la vez, de relieve, su punto de vista acerca de la importancia de la conservación de las tradiciones y usos locales. Así, por lo que respecta al sonido y la música del vídeo, cabe resaltar el uso, tanto al inicio como al cierre de la pieza, de una música prehispánica de autor desconocido. Además, junto con la canción de marimba utilizada como música de fondo; se aprecia como la banda sonora escogida se convierte en una verdadera declaración de intenciones: reivindicar la cultura y tradiciones guatemaltecas más arraigadas.

El montaje, tanto interno como de edición posterior; se convierten en mecanismo indispensable para la consecución de un producto final efectivo. En suma, cabe destacar que El Café, se resuelve como un ejercicio de enaltecimiento, revalorización y exaltación de los valores y el folclore regional más idiosincrásico. Los y las jóvenes realizadores/as de esta obra muestran un uso de los elementos narratológicos del Lenguaje Audiovisual muy eficientes; a través de los cuales consiguen trasladar al espectador una gran cantidad de significantes que (aunque, perpetuantes también de un imaginario patriarcal muy enraizado en las sociedades guatemaltecas) ellos/as mismos/as seleccionan como ciertamente característicos de su propia identidad.

\section{CONCLUSIONES: A MODO DE REFLEXIÓN FINAL}

Debido al doble objetivo (académico y registral) del material fílmico recogido, se decidió realizar dos piezas audiovisuales diferenciadas. El primero cuenta con un enfoque y carácter más testimonial, destinado al registro de los procesos de creación que allí se dieron (a modo de Documental Social Participativo). El segundo, producido por las mismas participantes; está compuesto por ocho vídeos grupales de unos cinco minutos de duración cada uno, junto con testimonios posteriores recogidos acerca de la opinión de los jóvenes sobre sus aprendizajes durante el proyecto (fruto todos ellos de la Técnica del Vídeo Participativo).

Por lo que respectiva al primero de ellos, se persiguió en todo momento disolver el posicionamiento dicotómico sujeto/objeto que plantea relaciones de poder desiguales (Foucault, 1986). De este modo, el/la realizador/a se convierte también en investigador/a quien, a su vez, participa activamente de aquello que pretende representar, propiciando de este modo cierta reversibilidad de la relación con el sujeto/colectivo representado.

[...] este enfoque participativo, en el que las interacciones forman en sí mismas parte del resultado final y su efecto, influye en el resultado de los acontecimientos; se convierte, asimismo, en una película de meta-observación. Los realizadores amplían sus observaciones para incluir el proceso de intercambio entre ellos mismos y sus sujetos de un modo sistemático y sustantivo. (Nichols, 1997, p. 85).

Determinadas huellas de autor, conocidas como marcas enunciativas, se alzaran aquí como aquel lugar desde el cual el observador interpreta y reflexiona acerca del fenómeno a estudiar; revelando cierta acción epistémica del sujeto pensante (investigador) sobre el objeto pensado (realidad social representada en formato audiovisual) de la cual nunca pretendimos despojar al producto audiovisual final.

Por lo que respecta a las piezas audiovisuales fruto de la implementación del VP, los/as jóvenes realizaron una apropiación total del medio y los dispositivos audiovisuales; Ilegando a realizar piezas con una alta carga simbólica y narrativa sorprendente, teniendo en cuenta la corta duración de las clases y talleres de capacitación impartidos al respecto. Todos y cada uno de los grupos supieron articular un mensaje a través del que expresaron qué era aquello que no les gustaba, cómo reivindicaban su posición como ciudadanos en el seno de la comunidad, y sobre todo, mediante una actitud muy constructiva y propositiva, qué actitudes y comportamientos podían llegar a modificar esos aspectos más negativos con los que no se sentían reflejados/as; para llegar a construir un cambio real.

Trabajando bajo la idea del entendimiento mutuo; ofreciendo una reflexión realizada por y desde los/as jóvenes participantes, se fomentó un tipo de relaciones mucho más horizontales y 
transparentes, rompiendo con las antes mencionadas clásicas relaciones dicotómicas.

No obstante, resulta primordial señalar que tanto o más importante que el producto final resultante de la implementación de la técnica del Vídeo Participativo, lo son los aprendizajes que se dan en el seno de los grupos, la construcción y deconstrucción de significados e imaginarios $y$, sobre todo, la democratización y reapropiación del lenguaje y los modos de representación propios del audiovisual los cuales, con suerte, se habrán convertido en una herramienta artística a la que lo/as participantes podrán recurrir a lo largo de sus trayectorias vitales.

\section{NOTAS}

${ }^{1}$ Disponible en: https://youtu.be/VZiAYc331oU.

2 Disponible en: https://youtu.be/VdrBHHluU84.

\section{REFERENCIAS BIBLIOGRÁFICAS}

- Austin, J. (1962). How to do things with words. Oxford: Oxford University Press.

- Bajtín, M. (1981). The Dialogic Imagination. Austin: University of Texas Press

- Beltrán, L.R. (1970). Communication in Latin America: persuasion for status quo or for national development? (Thesis for the degree of Ph.D.). East Lansing, Michigan State University, Department of Communication.

- Bourriaud, N. (2004). Postproducción. La cultura como escenario: modos en que el arte reprograma el mundo contemporáneo. Buenos Aires: Adriana Hidalgo Editora

- Bruner, J. (2004). Realidad mental y mundos posibles. Los actos de la imaginación que dan sentido a la experiencia, Barcelona Editorial Gedisa.

- Escobar, A. (2004). Más allá del Tercer Mundo: Globalidad imperial, colonialidad global y movimientos sociales anti-globalización. Revista Nómadas (20), 86-101.

- Fals-Borda, O. (1985). The Challenge of Social Change. London: Sage.

- Foucault, M. (1986). El uso de los placeres. Historia de la Sexualidad II. México: Siglo XXI.

- Garfinkel, H. (1967) Studies in ethnomethodology. New Jersey: Prentice Hall.

- Geertz, C. (1989). El antropólogo como autor. Barcelona: Paidós.
- Ibáñez, T. (2003). La construcción social del socioconstruccionismo: retrospectiva y perspectivas. Política Y Sociedad, 40 (1), 155 - 160. Recuperado de:

https://revistas.ucm.es/index.php/POSO/article/v iew/POSO0303130155A.

- Joxe, A. (2002). Empire of Disorder. Nueva York: Semiotext(e).

- Kaplún, M. (1998). Una pedagogía de la comunicación. Madrid: Ediciones de la Torre.

- Lunch, C. y Lunch, N. (2006). Una mirada al video participativo. Manual para actividades de campo. Oxford: InsightShare. Recuperado de: https://sgp.undp.org/images/Insights\%20into\%2 0Participatory\%20Video\%20-

$\% 20$ A\%20Handbook\%20for\%20the\%20Field\%20 Spanish.pdf.

- Nichols, B. (1997). La representación de la realidad: cuestiones y conceptos sobre el documental. Barcelona: Paidós Comunicación Cine.

- Pol, E. (2002). El modelo dual de la apropiación del espacio. En R.García Mira, J.M. Sabucedo y J.Romay (Eds.). Psicología y Medio Ambiente. Aspectos psicosociales, educativos y metodológicos (pp.123132). A Coruña: Asociación galega de estudios e investigación psicosocial

- Ricoeur, P. (1985). Temps et récit. I: L'histoire et le récit. Paris: Édition du Seuil 